\title{
Some effects of copulatory experience on postcastration mating behavior in the male hamster'
}

\author{
BRADFORD N. BUNNELL AND MARY EVE KIMMEL
}

UNIVERSITY OF FLORINA

\begin{abstract}
Abstraet
Intact male hamsters were first rated on sexual activity and then assigned to high and low experience conditions. Animals in the high experience condition received nine additional sexual activity trials while those in the low experience condition were placed with nonestrus females. The animals were then further divided into high experience gonadectomy (HG) and control (HC) groups and low experience gonadectomy (LG) and control (LC) groups. Early in postoperative testing, group HG showed significantly more sexual activity than group LG and group HC outperformed group LC.
\end{abstract}

\section{Problem}

It is generally accepted that experiential factors play a role in determining sexual behavior in male mammals (Young, 1961)。One such factor is copulatory experience itself. An approach to the study of this variable is to castrate animals with differential amounts of copulatory experience and to measure the persistence of sexual behavior after castration. There are many reports that, among experienced primates and carnivores, copulatory behavior can continue for years after castration (See Beach \& Pauker, 1948; Rosenblatt \& Aronson, 1958).

It has been more difficult to demonstrate this effect in rodents. Stone (1927) was unable to conclude that the differences he obtained between naive and sophisticated male rats were a result of experience. Rabedeau \& Whalen (1959) did not find that preoperative experience facilitated copulatory activity in castrated rats. The hamster, with its high level of sexual activity (Beach \& Rabedeau, 1959), might be a better $S$ than the rat. Beach \& Pauker (1949) suggested that some components of sexual activity persist longer in the hamster than in the rat, despite the fact that intromissions drop out at about the same time in both species. The purpose of the present study was to examine the effects of copulatory experience on postcastrational sexual activity in the male hamster.

\section{Method}

The Ss were 28 sexually naive male Syrian golden hamsters, 70-90 days old at the beginning of the experiment. They were housed, seven to a cage, in an air conditioned room which had a normal lightdark cycle. Ad lib feeding was supplemented by greens. Copulatory activity was tested in a 1-ft-square compartment inside a converted aquarium tank which was illuminated by a shaded 40 watt lamp.

Testing took place during the dark phase of the normal light-dark cycle。A trial was begun by placing the male in the apparatus for $5 \mathrm{~min}$. In sex testing, an estrus female was then introduced; on control trials a nonestrus female was used. Scoring was similar to that used by Beach \& Rabedeau (1959) except that a reliable behavioral criterion for ejaculations could not be found, and partial intromissions were included in scoring mounts. In addition, a sexual activity score (SAS) was computed by adding mounts and intromissions scores. It was used to estimate overall level of copulatory activity.

All animals were first given a 15-min. pre-experimental sexual activity trial followed three days later by a 5 -min. trial. The SAS on these trials was used to match animals in making assignments to the high and low experience conditions.

Fourteen animals were assigned to the high experience condition and were given nine more 5-min. sexual activity trials, with a minimum intertrial interval of three days. The remaining animals were assigned to the low experience condition. They received nine 5-min. control trials with a nonestrus female.

The animals were then divided into four groups. Five animals from the high experience condition were assigned to the High Experience Control Group ( $\mathrm{H} \approx$ ) such that they represented a broad range of different levels of sexual activity. The five animals in the low experience condition whose SAS scores on the pre-experimental trials were most like the scores of the animals in Group $\mathrm{HC}$ were placed in the Lou Experience Control Group (LC). The remaining nine animals from the high experience condition were assigned to the High Experience Gonadectomizid (iroup (HG) and the remaining nine animals from the low experience condition were assigned to the $L o w E x$ perience Gonadectomized Group (LG). The animals in both gonadectomy groups were castrated under Nembutal anesthesia and the animals in the control groups were given sham operations. Testing was resumed six days after surgery. Eight postoperative trials, spanning six weeks, were run using estrus females for all groups.

\section{Hesults}

Figure 1 gives the mean SAS data for all groups. (Performance on the initial 15-min. pre-experimental trial has been broken down into three 5-min. periods, making a total of thirteen preoperative trials.)

The postoperative SAS data were analyzed using a mixed factorial analysis of variance. ${ }^{2}$ The variables were Experience (high and low), Operations (castration and control), and Stages. Stages were used to assess 
the effect of trials. A stage was defined by combining SAS scores for two consecutive postoperative trials, making a total of four stages. (This was done to simplify computation and to minimize individual intertrial variability which was quite large due to the relatively short trial duration.)

Significant main effects were found for Operations $(F=72.74$, df $1,12, p<.01)$ and for Stages $(F=10.82$, df $3,72, p<.01)$. Experience was not significant $(F=4.42$, df $1,12, .10>p>.05)$. Neither the Experiencex Operation nor the Stages $\mathrm{x}$ Operation interactions were significant. The Stages $x$ Fxperience interaction was significant $(\mathrm{F}=9.80$, df $3,72, \mathrm{p}<.01)$.

Eight $\mathrm{t}$ tests were performed to determine the simple effects of the significant Stages $x$ Experience interaction. The only significant t's were found in the first stage (first and second postoperative trials) between groups HG and LG $(t=4.00, p<.05)$ and between groups HN and $\operatorname{LN}(t=3.04, p<.05)$.

When mounts and intromissions scores were examined, it was found that group LG made no intromissions following castration. Intromissions decreased more rapidly than did mounts in the HG group, such that the SAS scores of both castrate groups were composed only of mounts during the last stages of postoperative testing.

Results of analyses of variance of both mount latency and intromission latency scores (time from the beginning of a trial until a mount or an intromission, respectively, is acheived) were consistent with those obtained from analysis of the SAS data. Group LG had longer latencies than group $H G$ during the first few postoperative trials and, during these same trials, group LG performed more slowly than group HG. These differences disappeared later on as the HG latencies increased and the LG latencies decreased.

\section{Discussion}

The results show that experience has an effect upon postcastrational sexual activity in the male hamster. Under the testing conditions used, the differences obtained are short lived-the HG group performance drops quite rapidly to the level of the LG group and the LC group brings its performance up to that of the $\mathrm{HC}$ group. It appears that two factors may have been operating to produce the differences between groups of animals having different kinds of experience: One, a facilitative effect of copulatory behavior, the other a depressing effect due to the control trials with nonestrus females during which the females were frequently observed to attack the males. The relative importance of the two factors cannotbe determined from the present study, since the necessary control group is lacking.

In considering the facilitative effect of precastrational experience, it may be noted that gonadal androgen level should have been reduced to zero by the time the first postoperative trial was run. Neither adrenal androgen (Warren \& Aronson, 1956) nor secondary changes in the glands of the reproductive tract are known to affect the copulatory behavior of the castrated male

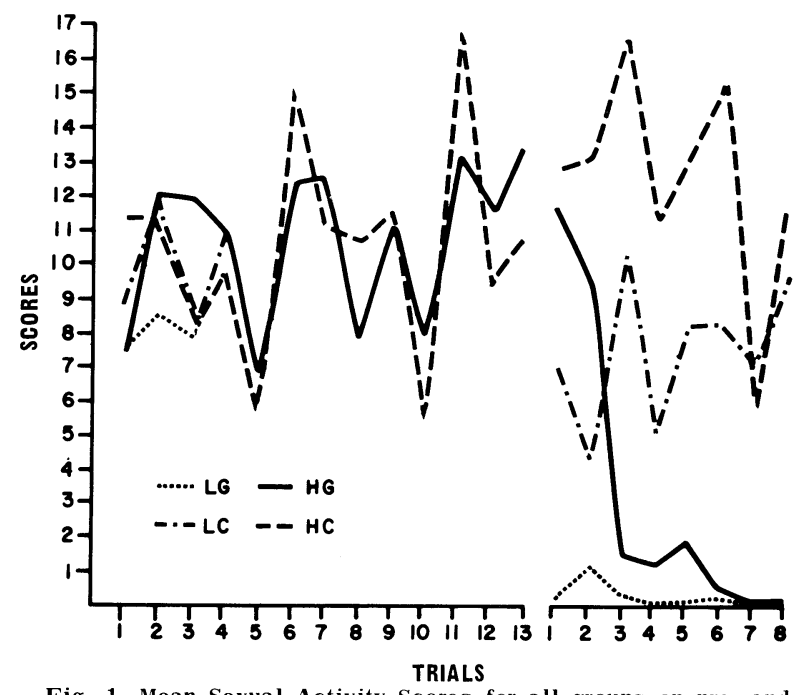

Fig. 1. Mean Sexual Activity Scores for all groups on pre- and post-operative trials. Low Experience Gonadectomized (LG), Low Experience Control (LC), High Fxperience Gonadectomized (HG), High Experience Control (HC).

hamster (Pauker, 1948). In terms of Beach's (1958) theory of a sexual arousal mechanism (AM), it may be suggested that sexual experience itself operates to sensitize the AM. In terms of conventional learning and motivation concepts, facilitation might be due either to increased habit strength or to an acquired approach drive. The use of either construct would lead to the prediction that an active extinction process may be necessary to eliminate all copulatory behavior in sexually experienced male castrates.

\section{Referenees}

Beach, F. A. Neural and chemical regulation of behavior. In H. F Harlow and C. N. Woolsey (Eds.), Biological and biochemical bases of behavior. Madison: University of Wisconsin Press, 1958.

Beach, F. A., \& Pauker, R. S. Effects of castration and subsequent androgen administration upon mating behavior in the male hamster (Cricetus auratus). Endocrinology, 1949, 45, 211-221.

Beach, F. A., \& Rabedeau, R. G. Sexual exhaustion and recovery in the male hamster. J. comp. physiol. Psychol., 1959, 52, 56-61.

Pauker, Roslyn S. The effects of removing seminal vesicles, prostate, and testes on the mating behavior of the golden hamster (Cricetus auratus). J. comp. physiol. Psychol., 1948, 41, 252-257.

Rabedeau, R. G., \& Whalen, R. E. Effects of copulatory experience on mating behavior in the male rat. J. comp. physiol. Psychol., 1959, 52, 482-484.

Rosenblatt, J. S., \& Aronson, L. R. The influence of experience on the behavioral effects of androgen in prepuberally castrated male cats. Anim. Behav., 1958, 6, 171-172.

Stone, C. P. The retention of copulatory ability in male rats following castration. J. comp. Psychol., 1927, 7, 269-287.

Warren, R. P., \& Aronson, L. R. Sexual behavior in castratedadrenalectomized hamsters maintained on DCA. Endocrinology, $1956,58,293-304$

Young, W. C. The hormones and mating behavior. In W. C. Young (Ed.), Sex and internal secretions, Vol. II. (3rd ed.) Baltimore: Williams and Wilkins, 1961.

\section{Notes}

1. Sponsored by grants G18646 and GB1149 from the National science Foundation to the senior author. This paper is from a Master's thesis by the junior author, dated December, 1962.

2. This statistical model was developed by Dr. H. D. Kimmel. Details may be obtained from him by writing in care of the Department of Psychology, University of Florida. 